\title{
MECHANICAL PROPERTIES AND MICROSTRUCTURE OF ULTRAFINE-GRAINED MAGNESIUM ALLOYS CONTAINING NEODYMIUM AND ZINC
}

\author{
${ }^{1}$ Stanislav ŠAŠEK, ${ }^{1}$ Jitka STRÁSKÁ, ${ }^{1}$ Peter MINÁRIK, ${ }^{2} J a n$ BOHLEN, ${ }^{3}$ Jiří KUBÁSEK \\ ${ }^{1}$ Charles University, Department of Physics of Materials, Czech Republic, Prague, EU, \\ sasekstanislav@seznam.cz \\ ${ }^{2}$ Helmholtz Zentrum Geesthacht, Magnesium Innovation Centre, Geesthacht, Germany, EU \\ 3University of Chemistry and Technology Prague, Faculty of Chemical Technology, Department of Metals \\ and Corrosion Engineering, Prague, Czech Republic, EU
}

https://doi.org/10.37904/metal.2019.765

\begin{abstract}
Two experimental magnesium alloys containing neodymium and zinc (Mg-5Nd-1Zn and Mg-1Nd-1Zn) were processed by severe plastic deformation (SPD) method - equal channel angular pressing (ECAP). The effect of SPD processing on the microstructure was studied by light microscopy (LM) and scanning electron microscopy (SEM) including electron backscatter diffraction (EBSD). A significant grain refinement was observed after 8 passes of ECAP in both alloys resulting in homogenous ultra-fine grained condition. Microstructure evolution significant affected mechanical properties, which were studied by microhardness measurements and compression deformation tests. Both yield compression strength $\sigma 0.2$ and microhardness significantly increased after ECAP when compared to the extruded or as-cast counterparts.
\end{abstract}

Keywords: Magnesium alloys, ultra-fine grained materials, equal channel angular pressing, electron backscatter diffraction

\section{INTRODUCTION}

Magnesium (Mg) is metal with the lowest density $\left(\rho=1740 \mathrm{~kg} \cdot \mathrm{m}^{-3}\right)$ among structural metals resulting in high specific strength, which can be utilized for weight saving in automotive industry and aerospace applications. [1]. Disadvantages include low Young's modulus, high chemical affinity and low corrosion resistance [2].

Materials used in aircraft manufacturing industry must meet strict technical standards. Recently, magnesium alloys were generally allowed for construction of passenger and crew seats in transport aircrafts by legally binding SAE Aerospace Standard (AS) 8049C [3]. However, a magnesium alloy must pass defined flammability test. Two magnesium alloys - Elektron 21 and WE43 successfully passed this specifically designed test, while the most common AZ31 alloy failed [4]. Lifting the ban on Mg-based alloys in aircraft industry creates a new stimulus for developing non-flammable (ignition-proof) high strength magnesium alloys.

Generally, elements that have high solubility limit in magnesium matrix and form only thermally stable intermetallic phases are considered as good candidates for materials with high strength and increased ignition temperature [5]. It was shown that $\mathrm{Nd}$ and $\mathrm{Gd}$ cause an increase of the ignition temperature in binary $\mathrm{Mg}$ alloys due to the existence of $\mathrm{Nd}_{2} \mathrm{O}_{3}$ and $\mathrm{Gd}_{2} \mathrm{O}_{3}$ surface oxides $[6,7,8]$.

Mechanical properties of polycrystalline materials depend on many parameters including the grain size. The relation between the strength and the grain size is given by Hall-Petch equation $[9,10]$ :

$\sigma_{0.2}=\sigma_{0}+k_{y} d^{-\frac{1}{2}}$

where $\sigma_{0.2}$ is the yield strength $(\mathrm{MPa}), \sigma_{0}$ is material constant for the starting strength for dislocation movement (MPa), $k_{y}$ is the strengthening coefficient (MPa. $\mathrm{m}^{1 / 2}$ ) and finally $d$ is the average grain size $(\mathrm{m})$. From equation 
(1) it follows, that the ultrafine-grained (UFG) materials have increased strength when compared to the coarsegrained ones. UFG materials can be produced by severe plastic deformation (SPD) techniques. The most frequently used current techniques of SPD are equal channel angular pressing (ECAP) [11], high pressure torsion (HPT) [12-15], accumulative roll-bonding (ARB) [16], twist extrusion [17] or multi-directional forging [18]. ECAP is widely used for its simplicity and good results [19].

In the present study, commercial magnesium alloy ZN11 alloy (1 wt\% of Zn and $1 \mathrm{wt} \%$ of $\mathrm{Nd}$ ) and newly developed alloy NZ51 with higher content of $\mathrm{Nd}(1 \mathrm{wt} \%$ of $\mathrm{Zn}$ and $5 \mathrm{wt} \%$ of $\mathrm{Nd}$ ) were studied. These alloys were processed by ECAP to achieve better mechanical properties especially increased strength.

\section{EXPERIMENTAL MATERIALS AND PROCEDURES}

ZN11 alloy (1 wt\% of zinc and $1 \mathrm{wt} \%$ of neodymium) was extruded at $400{ }^{\circ} \mathrm{C}$ with the extrusion ratio of 30 (ZN11 E). NZ51 alloy (1 wt. \% of zinc and 5 wt. \% of neodymium) was in as-cast state (NZ51 C).

Both alloys were processed by ECAP with the die with channels intersecting with the angle of $90^{\circ}$ using route $B_{C}$ pressing speeds of 3-10 mm. $\mathrm{min}^{-1}$ (increasing with the number of passes) [20]. Two billets were produced for each alloy - after one pass (1P) and after 8 passes (8P). ZN11 alloy was processed by ECAP at temperatures $250{ }^{\circ} \mathrm{C}$ (last pass) to $350^{\circ} \mathrm{C}$ (first pass) and NZ51 at $320^{\circ} \mathrm{C}$ (last pass) to $355{ }^{\circ} \mathrm{C}$ (first pass). Microstructure was investigated by scanning electron microscope (SEM) including EBSD and light microscope (LM). Mechanical properties were studied using microhardness measurement and compression tests. Microhardness was measured using Vickers hardness method with the load of $0.5 \mathrm{kgf}$ (HV 0.5) for loading time of $10 \mathrm{~s}$. More than 100 experimental points (indents) were evaluated for each specimen. Compression tests were performed on cuboid specimens with aspect ratio $3: 2(4 \mathrm{~mm} \times 4 \mathrm{~mm} \times 6 \mathrm{~mm})$.

\section{RESULTS AND DISCUSSION}

\subsection{Microstructure}

The microstructure of ZN11 alloy was observed by $L M$ in a plane perpendicular to the extrusion direction (ED) and is shown in Figure 1. Microstructure of extruded state is homogenous with average grain size $5-10 \mu \mathrm{m}$ in diameter. After ECAP, microstructure is more refined and therefore EBSD was utilized for observations. Inverse pole figure (IPF) maps of ZN11 alloy after 1 and 8 passes (1P and $8 \mathrm{P}$ ) are shown in Figure 2. Microstructure of ZN11 $1 \mathrm{P}$ is bimodal large grains ( $\sim 20 \mu \mathrm{m}$ in diameter) are surrounded by small grains $(\sim 3 \mu \mathrm{m}$ in diameter). Specimen after 8 passes is almost homogenous and contains grains about $1 \mu \mathrm{m}$ in diameter.

Figure 1 Microstructure of ZN11 E (extruded state)

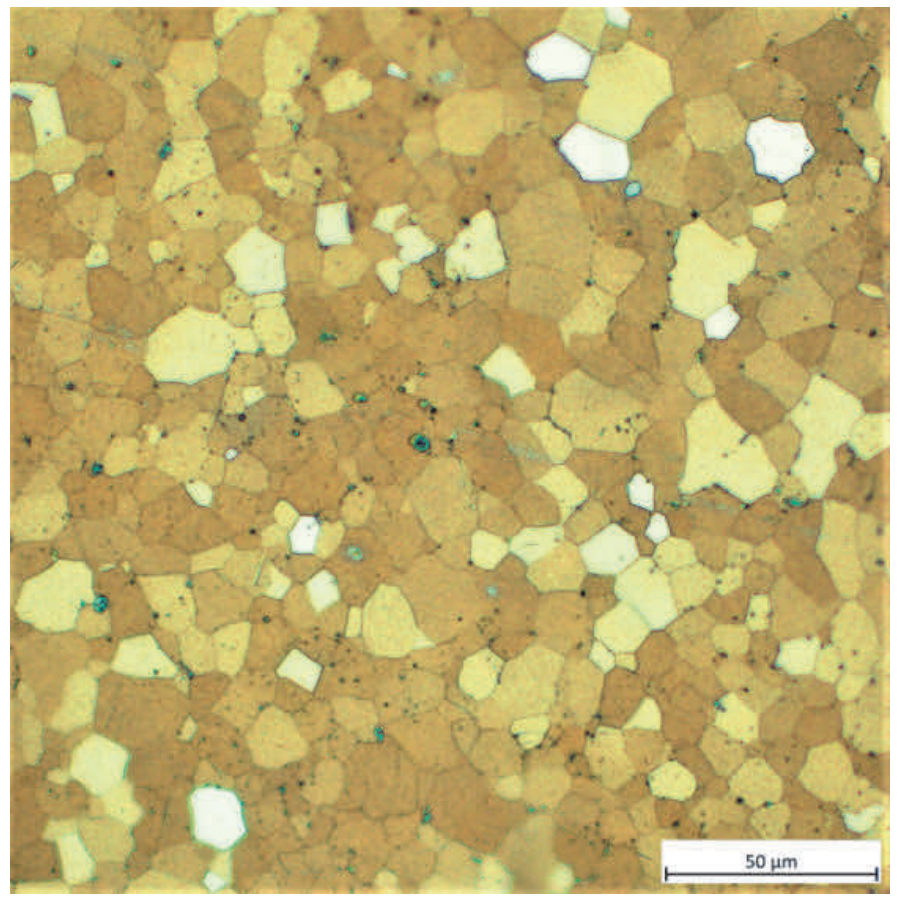



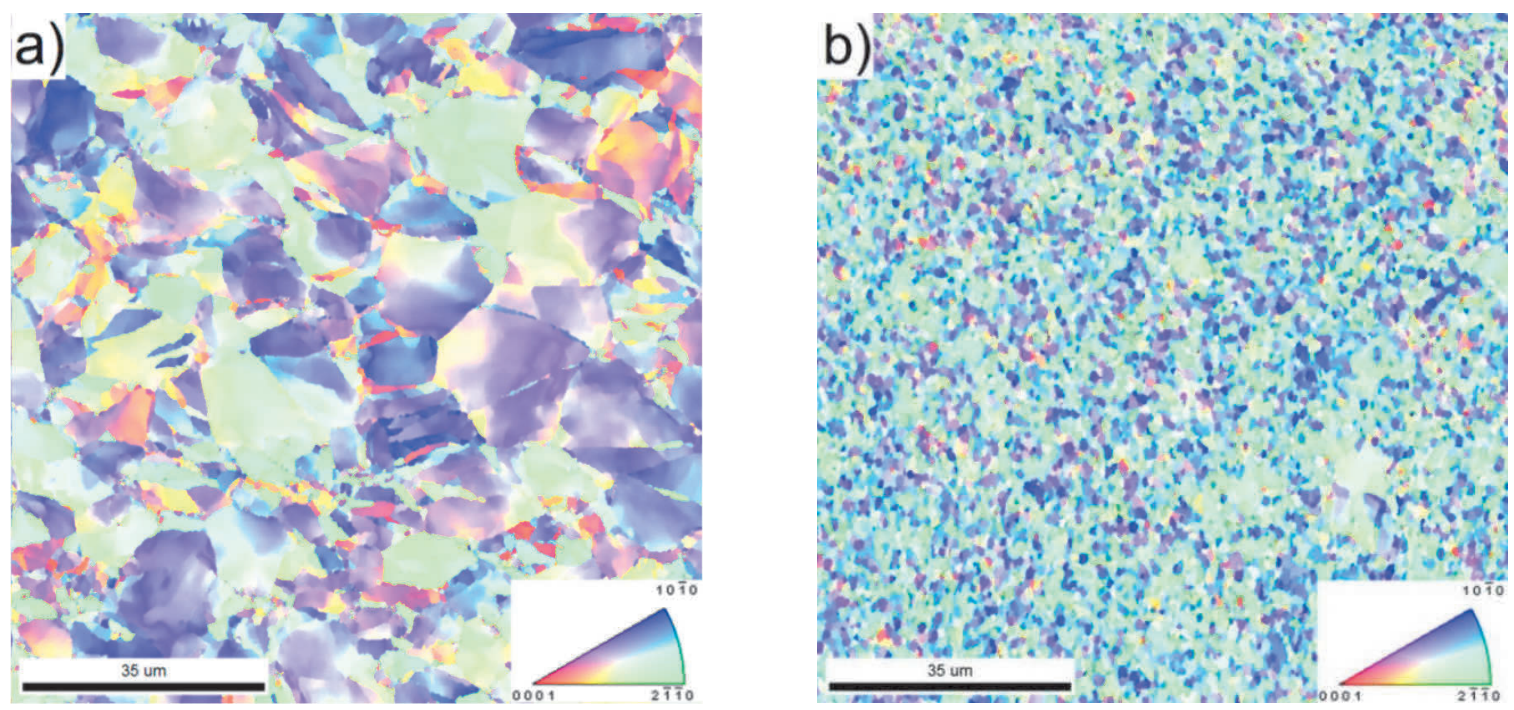

Figure 2 IPF maps of ZN11 a) 1P, 2) 8P

The microstructure of NZ51 is shown in Figure 3 . The cast material was produced in the shape of cylinder. It is clearly observed in Figure 3 that the microstructure is not homogenous - grains in the centre of cylinder are equiaxed while grains near the edge of the sample are elongated in the radial direction. Some of the grains are larger than $1 \mathrm{~mm}$ in diameter. After one ECAP pass (1P), many large grains remained in the specimen, but they were significantly deformed and some small grains formed around them (Figure 4a). The microstructure of NZ51 8P (Figure $4 b$ ) is similar to the case of ZN11 8P. Microstructure is fine grained and almost homogenous with the grain size about $1 \mu \mathrm{m}$ in diameter.

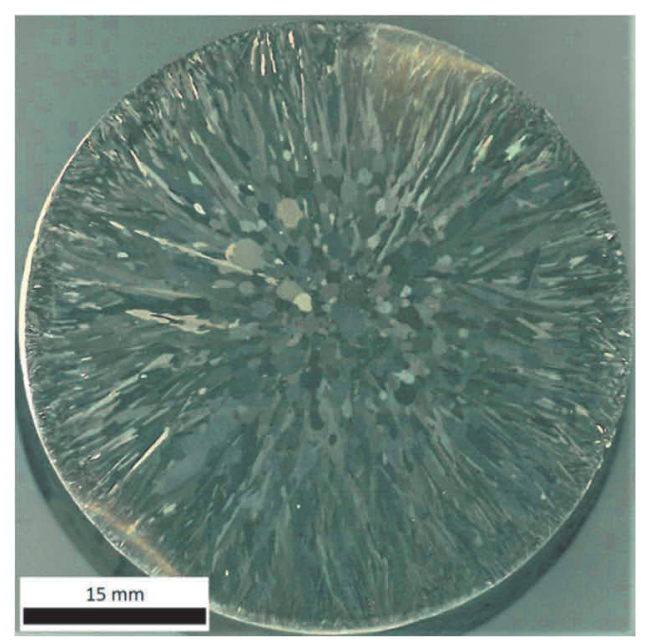

Figure 3 Microstructure of NZ51 (cast state)
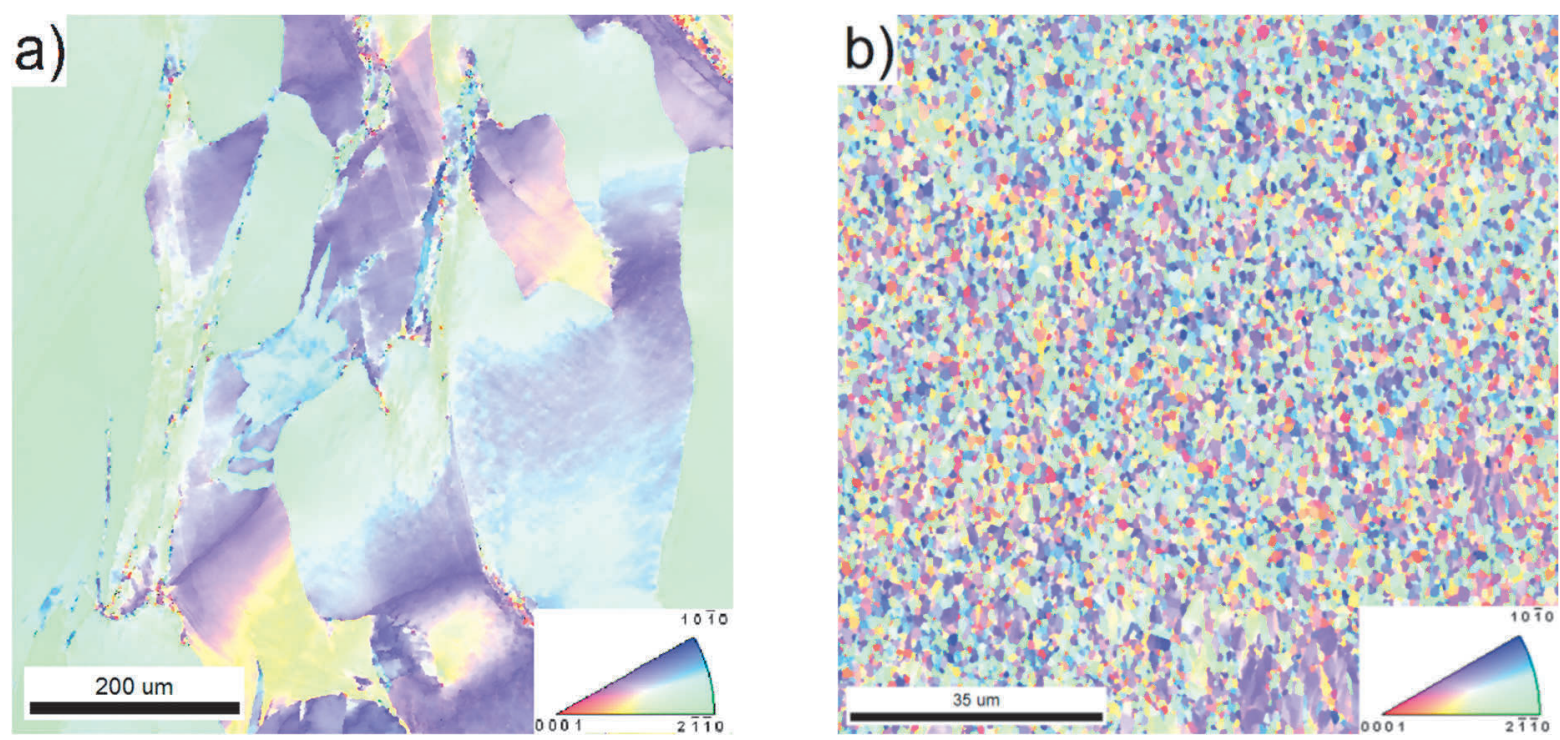

Figure 4 IPF maps of NZ51 a) 1P, b) 8P 
EBSD observations of microstructure can be used for determination of average grain size and fraction of highangle grain boundaries (HAGB). Achieved data are shown in Table 1. The fraction of HAGB significantly increased with the ECAP processing and reached for than $80 \%$ for the $8 \mathrm{P}$ states. This suggests matured, homogeneous UFG structure, with equilibrium grain size for given processing temperature and speed.

Table 1 Average grain sizes and fraction of high-angle grain boundaries (HAGB, missorientation angle $>15^{\circ}$ ) measured from EBSD

\begin{tabular}{|c|c|c|}
\hline Sample & Average grain size $(\mu \mathrm{m})$ & Fraction of HAGB $(\%)$ \\
\hline ZN11 1P & $8.6 \pm 6.2$ & 51 \\
\hline ZN11 8P & $1.1 \pm 0.6$ & 84 \\
\hline NZ51 1P & $520 \pm 260$ & 38 \\
\hline NZ51 8P & $1.2 \pm 0.7$ & 83 \\
\hline
\end{tabular}

\subsection{Mechanical properties}

Compression samples of ZN11 alloy were oriented such that the loading direction was parallel to the extrusion direction. In the case of NZ51 alloy, the material was taken from the centre of the as-cast cylinder and the loading direction was parallel to the axis of the as-cast cylinder.

Yield strength $\sigma_{0.2}$ and compressive strength $\sigma_{P}$ were evaluated from the deformation curves and achieved values are shown in Table 2. Yield strength of ZN11 increased dramatically after one pass of ECAP (ZN11 $1 \mathrm{P})$ and further after 8 passes. After 8 ECAP passes, yield strength was more than two times higher than for the extruded state ( 96 vs. $236 \mathrm{MPa}$ ). Compressive strength also increased, but not so significantly (from 268 to $351 \mathrm{MPa}$ ). Mechanical properties of NZ51 were also enhanced after one pass of ECAP, but the increase was not so large, which can be attributed to the limited refinement after 1P in NZ51 alloy. The differences between ZN11 1P and NZ51 1P can be explained by different initial states - the microstructural of NZ51 C was much coarser than the extruded one (ZN11 E). On the other hand, $\sigma_{0.2}$ and $\sigma_{P}$ are similar for both alloys in the case of samples after 8 ECAP passes. This is fully attributed to the equivalent microstructure consisting of small equiaxed grains.

Table 2 Yield strength $\sigma_{0.2}$ and compressive strength $\sigma_{P}$ of experimental materials

\begin{tabular}{|c|c|c|}
\hline Sample & $\sigma_{0.2}(\mathrm{MPa})$ & $\sigma_{P}(\mathrm{MPa})$ \\
\hline ZN11 E & $96 \pm 5$ & $268 \pm 9$ \\
\hline ZN11 1P & $173 \pm 6$ & $301 \pm 9$ \\
\hline ZN11 8P & $236 \pm 7$ & $351 \pm 16$ \\
\hline NZ51 C & $67 \pm 7$ & $174 \pm 7$ \\
\hline NZ51 1P & $98 \pm 6$ & $268 \pm 10$ \\
\hline NZ51 8P & $248 \pm 7$ & $354 \pm 15$ \\
\hline
\end{tabular}

The results of microhardness measurement are summarized in Table 3. Microhardness was not measured on NZ51 C due to its large grains. As you can see in Table 3, the results of microhardness has very similar upward trend like the compressive strength for both alloys.

Table 3 Microhardness results

\begin{tabular}{|l|c|c|c|c|c|}
\hline Sample & ZN11 E & ZN11 1P & ZN11 8P & NZ51 1P & NZ518P \\
\hline Microhardness HV 0.5 & $48 \pm 1$ & $64 \pm 2$ & $75 \pm 2$ & $55 \pm 3$ & $79 \pm 2$ \\
\hline
\end{tabular}




\section{CONCLUSION}

The effect of severe plastic deformation by ECAP on microstructure of magnesium alloys containing neodymium and zinc (ZN11 E and NZ51 C) was studied. Initial extruded state of ZN11 E has homogenous microstructure with average size of grains of approx. $20 \mu \mathrm{m}$. The microstructure after one pass (ZN11 1P) was bimodal with large initial grains from extrusion $(\sim 20 \mu \mathrm{m})$ and newly formed small $(\sim 3 \mu \mathrm{m})$ grains. The microstructure of NZ51 C was very coarse and non-homogenous. One pass of ECAP led to deformed structure of NZ51 alloy without significant fragmentation. After 8 ECAP passes, the microstructure of both alloys was significantly refined with average grain size $1 \mu \mathrm{m}$, homogeneous and containing more than $80 \%$ of HAGB. Grain refinement led to improvement of mechanical properties - yield strength, compressive strength and microhardness. It is concluded that ECAP processing of ZN11 and NZ51 magnesium alloys was successful in terms of microstructural refinement and improvement of strength.

\section{ACKNOWLEDGEMENTS}

The presented work was financially supported by GACR project 19-08937S.

\section{REFERENCES}

[1] GUPTA, M. and NAI, Mui Ling Sharon. Magnesium, magnesium alloys, and magnesium composites. New York: John Wiley, 2011. ISBN 978-047-0494-172.

[2] MORDIKE, B. L. and EBERT, T. Magnesium: Properties - applications - potential. Materials Science and Engineering: A. 2001, vol. 302, no. 1, pp. 37-45.

[3] Performance standard for seats in civil rotorcraft, transport aircraft, and general aviation aircraft AS8049C, revised 14. 8. 2015, https://www.sae.org/standards/content/as8049c/, applicable to 9.4.2018.

[4] MARKER, T. R. Development of a Laboratory Scale Flammability Test for Magnesium Alloys Used in Aircraft Seat Construction, Federal Aviation Administration report: DOT/FAA/TC-13/52, 2014 https://www.fire.tc.faa.gov/pdf/TC13-52.pdf, applicable to 9.4.2018.

[5] FONTANA, M. G. Corrosion Engineering. McGraw-Hill int., New York 1986

[6] KIM, Y. M., YIM, C. D., KIM, H. S. and YOU, B. S., Key factor influencing the ignition resistance of magnesium alloys at elevated temperatures. Scripta Mater. 2011. vol. 65, pp. 958-961.

[7] AYDIN, D. S., BAYINDIR, Z., HOSEINI, Z., M. and PEKGULERYUZ, M.O., The high temperature oxidation and ignition behavior of Mg-Nd alloys. Part I: The oxidation of dilute alloys, J. Alloys Compd. 2013, vol. 569, pp. 35-44.

[8] AYDIN, D. S., BAYINDIR, Z. and PEKGULERYUZ, M.O., The high temperature oxidation behavior of Mg-Nd alloys. Part II: The effect of the two-phase microstructure on the on-set of oxidation and on oxide morphology, J. Alloys Compd. 2014. Vol. 584, pp. 558-565.

[9] HALL, E.O. The Deformation and Ageing of Mild Steel: III Discussion of Results. Proceedings of the Physical Society. Section B. 1951. vol. 64, no. 9, pp. 747-753.

[10] PETCH, N.J. The cleavage strength of polycrystals. Journal of the Iron and Steel Institute London. 1953. vol. 173 pp. 25-28.

[11] LANGDON, T.G. The principles of grain refinement in equal-channel angular pressing. Materials Science and Engineering A. 2007. vol. 462, pp. 3-11.

[12] ZHILYAEV, A.P. and LANGDON, T.G. Using high-pressure torsion for metal processing: Fundamentals and applications. Progress in Materials Science. 2008. vol. 53, pp. 893-979.

[13] KIM, H.S. Finite element analysis of high pressure torsion processing. Journal of Materials Processing Technology. 2001. vol. 113, pp. 617-621.

[14] YOON, E.Y., LEE, D.J., KIM, T.-S., CHAE, H.J., JENEI, P., GUBICZA, J., UNGÁR, T., JANEČEK, M., VRÁTNÁ, J., LEE, S. and KIM, H.S. Microstructures and mechanical properties of Mg-Zn-Y alloy consolidated from gasatomized powders using high-pressure torsion. Journal of Materials Science, 2012. vol. 47, pp. 7117-7123. 
[15] VRÁTNÁ, J., JANEČEK, M., ČíŽEK, J., LEE, D.J., YOON, E.Y. and KIM, T.S. Mechanical properties and microstructure evolution in ultra-fine grained AZ31 alloy processed by severe plastic deformation. Journal of Materials Science. 2013. vol. 48, pp. 4705-4712.

[16] SAITO, Y., UTSUNOMIYA, H., TSUJI, N. and SAKAI, T. Novel ultra-high straining process for bulk materialsdevelopment of the accumulative roll-bonding (ARB). Acta Materialia. 1999. vol. 47, pp. 579-583.

[17] VARYUTKHIN, V.N., BEYGELZIMER, Y., SYNKOV, S. and ORLOV, D. Application of Twist Extrusion. Materials Science Forum. 2006. vol. 503-504, pp. 335-340.

[18] YANG, X., OKABE, Y., MIURA, H. and SAKAI, T. Effect of pass strain and temperature on recrystallisation in magnesium alloy AZ31 after interrupted cold deformation. Journal of Materials Science. 2012. vol. 47, pp. 28232830.

[19] MINÁRIK, P., VESELÝ, J., KRÁL, R., BOHLEN, J., KUBÁSEK, J., JANEČEK, M. and STRÁSKÁ, J. Exceptional mechanical properties of ultra-fine grain Mg-4Y-3RE alloy processed by ECAP. Materials Science \& Engineering A, 2017. vol. 708, pp. 193-198.

[20] VALIEV, R. Z. and LANGDON, T. G. Principles of equal-channel angular pressing as a processing tool for grain refinement. Progress in Materials Science. 2006. vol. 51, pp. 881-981. 